dilutions for phage inactivation and $0.1 \mathrm{ml}$. was used for assaying antibodies by the immunoadsorbent technique. The results of three repeat experiments tested by the modified phage technique (Table 1) indicate that treatment with BADL reduced the incidence of antibody forming cultures (5/17 in the experimental as compared with $16 / 16$ in the control groups). Experiments 2 and 3 (Table 1) indicate that, unlike DNP-lysine, BADL prevented antibody production even when the antigen was applied $44 \mathrm{~h}$ after the removal of the affinity labelling reagent. Fig. 1 shows, moreover, that DNP-lysine had a limited effect in inhibiting antibody production to DNP by DNP-RSA, whereas BADL and BADE had a marked inhibitory effect. Table 1. EFEECT OF BADL ON THE SECONDARY RESPONSE TO DNP INDUCED
in vitro BY DNP-HARMOCYANIN AND ASSAYED BY THE MODIFIED PHAGE in vitro BY DNP-HAFMOCYANIN AND ASSAYED BY THE MODIFIED PHAGE

\begin{tabular}{ccccc} 
Expt. & $\begin{array}{c}\text { Treatment of } \\
\text { spleen donor }\end{array}$ & $\begin{array}{c}\text { Treatment of } \\
\text { spleen explants }\end{array}$ & $\begin{array}{c}\text { Time of } \\
\text { antigen } \\
\text { challenge } \\
\text { (h) }\end{array}$ & $\begin{array}{c}\text { Incidence of } \\
\text { reactive } \\
\text { cultures (50 } \\
\text { per cent } \\
\text { inactivation) }\end{array}$ \\
\multirow{2}{*}{1} & $\begin{array}{c}\text { Immunized } \\
\text { Immunized }\end{array}$ & BADL in PBS & 4 & $2 / 10$ \\
& $\begin{array}{c}\text { Untreated } \\
\text { control }\end{array}$ & - & 15 & $5 / 5$ \\
& Immunized & BADL in PJS & - & $0 / 4$ \\
& Immunized & DNP-lysine & 24 & $2 / 4$ \\
& Immunized & PBS, control & 24 & $4 / 4 *$ \\
3 & Immunized & Medium, control & 24 & $4 / 4$ \\
& Immunized & BADL in PBS & 48 & $1 / 3$ \\
& Immunized & DNP-lysine & 48 & $3 / 3$ \\
& Immunized & PBS, control & 48 & $3 / 3$
\end{tabular}

* All these cultures responded at a low rate of antibody formation, manifested in 50-80 per cent of inactivation of the modified phage. When tested by the immunoadsorbent technique, these samples yielded an average c.p.m. of 7,207 as compared with $\mathbf{1 6 , 0 8 9}$ in the accompanying PBS control group.

Similar results were obtained in an additional experiment in which the medium samples were assayed by the immunoadsorbent technique (Table 2). Both reagents, BADL and BADE, reduced the antibody response considerably, assessed here in counts per minute.

To test the specificity of the inhibition obtained by BADL and BADE, the effect of these reagents on the response to a non-crossreacting antigen was studied. Spleen explants were obtained from mice immunized with poly-DL-alanyl-RSA. The capacity of BADE and BADL to inhibit antibody production to the poly-DLalanine hapten in these explants was then tested. The results (Table 2 and Fig. 2) indicate that there was no

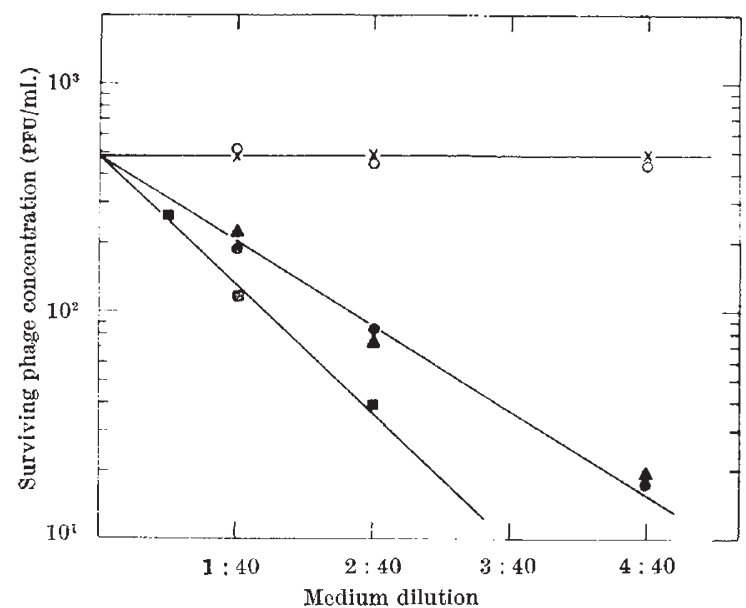

Fig. 2. The effect of BADL and BADE on antibody production in vitro in the poly-DL-alanyl system. The curves show inactivation of poly-D-alanyl- $T_{a}$ phage by medium from spleen explants that were induced for secondary response in vitro by poly-DL-alanyl-RSA. The incubation of phages and medium was for $4 \mathrm{~h}$. $x$, Explants from normal animal, control; $O$, explants from primed animal without in vitro stimulation with poly-DL-alanyl-RSA; PBS alone before antigen; $\boldsymbol{A}$, explants incubated with BADE befor antigen; explants incubated with BADL before antigen.
Table 2. EFFECT OF BADL AND BADE ON THE SECONDARY RESPONSE TO DNP AND TO POLY-DL-ALANINE INDUCED in vitro BY DNP-HAEMOCYANIN

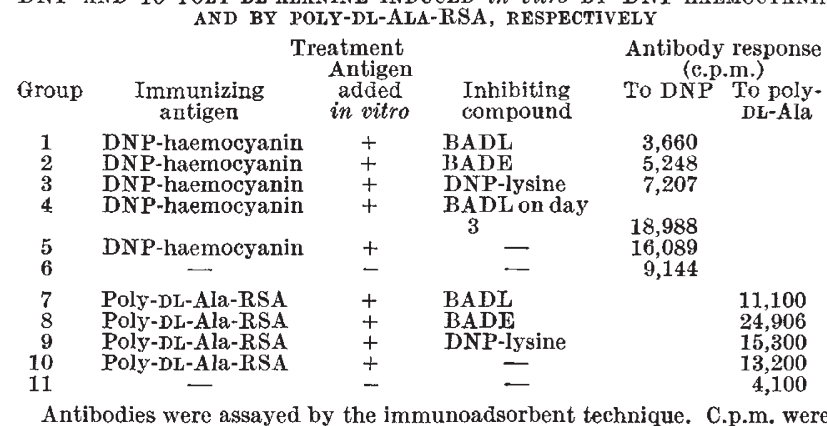
determined on samples of pools of media from four cultures in each case.

inhibitory effect on the production of antibodies to the non-crossreacting hapten.

The results cannot be attributed to a non-specific toxic effect manifested in inhibition of antibody production because (a) BADL and BADE did not completely eliminate antibody production but reduced it to the residual levels found in cultures which were not challenged by antigen in vitro (Fig. 1), and (b) when the reagents were added to the explants 3 days after the antigen, no inhibition of the response could be detected (Table 2 and Fig. 1). Furthermore, the inhibitory effect of the affinity labelling compounds was found to be specific, for BADL and BADE did not block the response to poly-DL-alanine.

In summary, it is shown that BADL and BADE inhibit specifically the production of anti-DNP antibodies; and the effect, unlike that of free haptens such as DNP. lysine, persists for at least $44 \mathrm{~h}$. In analogy with the affinity labelling of anti-DNP antibodies by BADL and BADE, we conclude that these reagents become covalently bound to antibody-like molecules on the cell surface of the spleen explants, which may represent the antigen recognition receptors of the antigen-reactive cells.
S. Segal
A. Globerson
M. FELDMAN
J. HAIMOVICH
D. Givol

Departments of Cell Biology

and Chemical Immunology,

The Weizmann Institute of Science,

Rehovot,

Israel.

Received June 16, 1969.

${ }^{1}$ Miller, J. F. A. P., and Mitchell, G. F., Proc. US Nat. Acad. Sci., 59, 296 (1968).

${ }^{2}$ Mitchison, N. A., Cold Spring Harbor Symp. Quant. Biol., 32, 431 (1967).

${ }^{3}$ Sell, S., J. Exp. Med., 125, 289 (1967).

4 . Exp. Med., 125, 393 (1967).

${ }^{5}$ Weinstein, Y., Wilchek, M., and Givol, D., Biochem. Biophys. Res. Commun. (in the press).

${ }^{6}$ Globerson, A., and Auerbach, R., J. Exp. Med., 124, 1001 (1966).

${ }^{7}$ Haimovich, J., and Sela, M., $J$. Immunol., 97, 338 (1966).

${ }^{8}$ Carter, B. G., Yo, S. I., and Sehon, A., Canad. J. Bicchem., 46, 261 (1968).

${ }^{9}$ Robbins, J. B., Haimovich, J., and Sela, M., Immuncchemistry, 4, 11 (1967).

${ }^{10}$ Klinman, N. R., and Taylor, R. B., Clin. Exp. Immunol., 4, 473 (1969).

\section{Transfer of Immunity against Long Surviving Rat Skin Xenografts by Antilymphocyte Serum treated Syrian Hamsters}

Xenografts, that is, grafts of which donor and recipient are members of different species, are, as a general rule, destroyed even more rapidly than allografts of similar 
tissue. Until recently all procedures that were effective in prolonging the lives of allografts - for example, induction of immunological tolerance in the host, treatment of the host with immunosuppressive agents and so on-were usually ineffective for sustaining xenogeneic grafts. These empirical observations led to the suggestion that nonimmunological factors, for example, syngeneic preference, metabolic shortcomings of the host and so on, may underlie the failure of xenografts to thrive $e^{1,2}$.

The recent demonstrations ${ }^{3,4}$ that mice treated with heterologous antilymphocyte serum (ALS), an extremely powerful immunosuppressant, will, however, consistently retain skin grafts from donors of very remote genetic relationship, for example, rats, guinea-pigs, rabbits or even humans, made virtually untenable the belief that the failure of xenografts is attributable to non-immuno. logical factors. The work to be reported here shows that ALS treatment effectively overcomes the Syrian hamster's resistance to xenografts; it also suggests a method for identifying the mediator(s) of xenograft rejection.

The ALS was raised in rabbits against hamster lymph node cells ${ }^{5}$ and had a lymphoagglutinin titre between $1: 400$ and $1: 800$ (ref. 6). Carefully fitted, full thickness, trunk skin grafts approximately $2 \mathrm{~cm}$ in diameter were transplanted (day 0) according to standard procedures?. Dressings were removed for primary inspection on the seventh day and the grafts were subsequently inspected at 2 to 3 day intervals. Their viability was assessed on the basis of outward appearance ${ }^{7}$, and confirmed in many instances by histological examination of biopsy specimens.

The recipients, adult hamsters of the MHA isogenic strain weighing 80-110 g, were treated with ALS (in the case of experimental animals) or normal rabbit serum (for controls) according to the following regimen: $2 \mathrm{ml}$. of whole serum was injected intraperitoneally daily from day -7 to 0 and three times per week thereafter. Consonant with the findings of others ${ }^{1,3,4}$ it was necessary to pretreat the xenograft recipients with ALS in order to prolong significantly the life of their grafts; this is not necessary for allografts (unpublished results of C. F.S. and $W$. J. Donawick).

Table 1. SURVIVAL TIMES FOR FULL THICKNESS SKIN XENOGRATIS ON ADULT SYRIAN HAMSTERS
Host species

Syrian hamster

(Mesocricetus auratus)

\section{Donor species}

Kurdistan hamster (Mesocricelus brandti) (Cricetulus griseus)
Chinese hamstcr Rat

Mouse
Survival times of xenografts on ALS*
treated hosts (days) $71 ; 2 \times>100$

$3 x>100$

$55,72,78,81,4 \times 86$, $55,72,78,31,4 \times 86$,
$\quad 3 \times 90 ; 14 \times>100$
$5 \times>100$
* Panels of normal rabbit scrum treated syrian hamsters universally rejected any of the tested xenografts in $<14$ days.

Hamsters treated with rabbit anti-hamster lymphocyte serum routinely retained skin xenografts for 100 days or more from a variety of donor species (Table l), including Kurdistan and Chinese hamsters, rats and mice. Nono of the long-surviving xenografts on hamsters showed any sign of degeneration or of the mononuclear cell infiltration suggestive of chronic host reactivity ${ }^{7,8}$. In other words, although the xenografts in these experiments were observed for maximum periods of 100 days, there is every reason to believe that those grafts would have survived very much longer if ALS treatment had been continued.

Once ALS therapy was stopped, however, all the established xenografts had consistont and well defined "coasting periods", that is, periods between cessation of ALS therapy and rejection of the grafts. These proved to be independent of the length of the preceeding ALS treatment; grafts of 30 days' standing coasted for as long after the cessation of ALS treatment as those which were 100 days old at the termination of therapy. During the coasting noriod the grafts appeared, at least grossly, to be perfectly healthy, and when rejection finally occurred it was invariably prccipitous. Usually no more than 1 day intervened between the appearance of the first outward signs of epithelial breakdown and reduction of the graft to a dry scab.

Advantage was taken of the "coasting phenomenon" to try to elucidate the causes of xenograft immunity. Rat and mouse skin xenografts placed contralaterally on the samo ALS-treated recipient both generally enjoyed a coasting period of about 20 days ( $\pm 1-2$ days) (Table 2 ). If, however, hosts bearing such grafts were injected intravenously with $400 \times 10^{6}$ lymph node cells from isologous donors (the lymphoid cell donors being in the final throes of actively rejecting "second-set" rat skin xenografts), the rat skin xenografts on the animals receiving the cell inocula underwent precocious rejection (median coasting period < 11 days) while the control contralateral mouse skin grafts remained in a hoalthy condition. The latter observation indicates at least a species specificity for this transferred immune state.

Rejection of rat xenografts by hamsters whose immune machinery had been reconstituted through the transfer of sensitized lymph node cells was invariably accompanied by the "walling off" of the graft by a large accumulation of mononuclear cells interspersed with a few eosinophils. Death of the graft, in these circumstances, may therefore have been chiefly caused by ischaemic necrosis. The existence of a moderate degree of mononuclear cell infiltration in the graft stroma, howover, may indicate that the cellular factors responsible for the rejection of solid tissue allografts ${ }^{9}$ were also involved.

Table 2. A COMPARISON OF THE ABIJTTY OF TRANSFERRED PUTATIVELY IMMUNE ISOTOCOUS LYMPH NODE CELLS AND SERUM TO PRECIPITATE THR REJECTION OF LONG ESTABLISHED RAT SKIN XENOGRAFTS ON ALS-TREATET HAMSTERS WHICH ALSO PFAR LONG-STANDING CONTIALATERAL MOLSE TRLNI
SKIN XENOGRAFTS

\begin{tabular}{|c|c|c|c|}
\hline $\begin{array}{l}\text { Number } \\
\text { of } \\
\text { animals } \\
\text { tested }\end{array}$ & 'Treatment of the host & $\begin{array}{l}\text { Approximate } \\
\text { median coasting } \\
\text { period (and } \\
\text { range) for rat } \\
\text { skin xenografts } \\
\text { (days) }\end{array}$ & $\begin{array}{l}\text { Approximate } \\
\text { median coasting } \\
\text { period (and } \\
\text { ralige) for mouse } \\
\text { skin xenografts } \\
\text { (days) }\end{array}$ \\
\hline $\begin{array}{r}12 \\
7\end{array}$ & $\begin{array}{l}\text { ALS days }-7 \text { to }+50 \\
\text { ALS days }-7 \text { to }+50 \text {; then } \\
400 \times 10^{6} \text { viable hamster } \\
\text { anti-rat lymph node cells } \\
\text { intraperitoneally on day } \\
+52\end{array}$ & $\begin{array}{ll}20 \cdot 0 & (18-21) \\
10 \cdot 5 & (9-11)\end{array}$ & $\begin{array}{l}21 \cdot 0(19-22) \\
20 \cdot 5(19-21)\end{array}$ \\
\hline 6 & $\begin{array}{l}\text { ALS days }-7 \text { to }+50 \text {; then } \\
4 \text { ml. of hamster anti-rat } \\
\text { antiserum intraperitoneally } \\
\text { on day }+52\end{array}$ & $20 \cdot 0(2 C-21)$ & $21 \cdot 0(18-22)$ \\
\hline
\end{tabular}

All attempts to procure rejection of well established rat skin grafts on hamsters by transferring as much as $4 \mathrm{ml}$. of putatively immune serum were unsuccessful (Table 2). There are three possible explanations for this success of lymphoid cell inocula in transferring immunity to xenografts and the failure of scrum. (a) Rejection of skin xenografts (at least in the present species combination) is mediated primarily by a cellular immunity. (b) The notorious inability of Syrian hamsters to produce circulat. ing isoantibodies ${ }^{10}$ extends to their ability to produce heteroantibodies, precluding the participation of humoral factors in the process of xenograft rojoction in this species. Or (c) antibodies against xenografts are produced in such small quantities that at any given time the amounts present in the blood are insufficient to transfer immunity by passaging serum, whereas viable antibody producing cells, whon transferred, continue to make antibodies the cumulative effects of which are sufficiont to bring about, the rejection of a xenograft.

Antilymphocyto serum has already been used clinically for tho abrogation of allograft immunity ${ }^{11,12}$. The present studies extend to a new species combination an earlier observation ${ }^{1}$ that mammalian tissues of very distant genetic relationship can grow and flourish in close proximity in vivo over periods of several months and perhaps indefinitely. Furthormore, the results suggest that the unique capacity of ATS to sustain xenograft survival may be used as a tool to determine mechanisms 
for destroying interspecies grafts, a group of immune reactions about which we at present know very little ${ }^{13,14}$.

This work was supported in part by the US Public Health Servise and by a Pennsylvania Plan scholarship. I thank Professor R. E. Billingham for his encouragement and helpful criticism and Mr George Sawchuck for technical assistance.

Department of Medical Genetics,

C. F. SHAFFER

School of Medicine,

University of Pennsylvania,

Philadelphia, Pennsylvania.

Received May 30; revised Angust 11, 1969.

${ }^{1}$ Lance, E. M., and Medawar, P. B., Lancet, i, 1174 (1968).

${ }^{2}$ Loeb, L., in The Biological Basis of Individuality, 116 (Thomas, Springfield, 1945). ${ }^{3}$ Monaco, A. P., Wood, M. L., Gray, J. G., and Russell, P. S., J. Immunol.,
96, 229 (1966).

${ }^{4}$ Levey, R. H., and Medawar, P. B., Proc. VS Nat. Acad. Sci., 56, 1130 (1966).

¿Gray, J. G., Monaco, A. P., Wood, M. I., and Russell, P. S., J. Immunol. 96, 217 (1966)

${ }^{6}$ Amos, D. B., and Peacocke, N., in Proc. Ninth Cong. Europ. Soc. Haemat. (Lisbon), 1132 (S. Karger, Basel and New York, 1963).

- Billingham, R. E., in Transplantation of Tissues and Cells (edit. by Billingham, R. E., and Silvers, W. K.), 1 (Wistar Inst. Press, Philadelphia, 1961).

${ }^{8}$ Hildemann, W. H., and Walford, R. I., Ann. NY Acad. Sci., 87, 56 (1960).

- Waksman, B. H., Lab. Invest., 12, 46 (1963).

${ }^{10}$ Palm, Joy, Silvers, W. K., and Billingham, R. E., J. Heredit., 58, 40 (1967)

${ }^{11}$ Starzl, T. E., Marchioro, T. L., Porter, K. A., Iwasaki, Y., and Cerilli, G. J., Surg. Obstet. Gynec., 124, 301 (1967).

12 Starzl, T. F., Porter, K. A., Iwasaki, Y., Marchioro, T. L., and Kashiwagi, N., in Antilymphocytic Serum, 4 (Ciba Foundation Symp., Little, Brown and Compauy, Boston, 1967).

${ }^{13}$ Algire, G. H., Weaver, J. M., and Prehn, R. T., Ann. NY Acad. Sci., 64, 1009 (1957).

14 Hašek, M., Folia Biol., 8, 57 (1962).

\section{Therapy of Transplantable Mouse Leukaemias with Antileukaemia Sera}

THE therapy of leukaemias by the administration of heterologous antisera has been tested both in experimental animals ${ }^{1-5}$ and in patients $s^{6,7}$, but the results have been variable and confusing. This article seeks to explain these discrepancies and indicates how positive results might be obtained.

Leukaemia cells are malignant forms of lymphocytes, so that antileukaemia sera are closely related to antilymphocyte sera (ALS). Recently, ALS has been used widely for prolongation of allograft survival ${ }^{8-11}$ and some of this experience is directly applicable to trials of antileukaemia sera. We have previously studied in vitro the specificities of rabbit antisera to various types of mouse lymphocytes ${ }^{12}$. Because antileukacmia sera were slightly more specific against leukaemia cells than was ALS, antileukaemia sera were used exclusively. though this does not exclude the possibility that ALS might also be effective.

Three congenic leukaemias were transplanted intraperitoneally in congenic mice: Gardner lymphosarcoma 6C3HED of $\mathrm{C} 3 \mathrm{H}$ strain ${ }^{13-15}$, transplanted in the low mammary tumour substrain $\mathrm{C} 3 \mathrm{HeB} / \mathrm{FeJ}$; lymphocytic leukaemia L1210 of DBA/2J mice m-15; $^{13}$ and leukaemia RA5 of AKR/J mice ${ }^{13-15}$. Groups of three or more rabbits were hyperimmunized by two courses of injections, each of which consisted of a single subcutaneous injection (intramuscular injections have since been found to be preferable) of approximately twenty million leukaemia cells in com. plete Freund-McDermott adjuvant, followed by five to seven intravenous injections of approximately thirty million viable cells in isotonic saline, given twice weekly. Rabbits were bled 7 to 10 days after the last injection. Antisera were inactivated for 30 min at $56^{\circ} \mathrm{C}$ and stored at $-20^{\circ} \mathrm{C}$.
Serial doubling dilutions of antisera were titred against leukaemia cells by immune cytolysis ${ }^{16,17}$. Because potency is proportional to the reciprocal of titre, it was conveniently expressed as 100/cytolytic titre. For therapy experiments, potency units were used that depended on the volume administered, as well as on the potency of the antiscrum. Potency units were calculated as 100/cytolytic titre $\times$ volume of antiserum injected (mI.). For therapy trials in vivo, we used the standard assay system (Table 1) considered to be one of the most helpful for selection of clinically useful chemotherapeutic materials ${ }^{18}$. Treatment was only effective when many units of cytolytic potency were administered, but antisera with high cytolytic potency were usually highly toxic: within $1 \mathrm{~h}$ after intraperitoneal injection of $0.1 \mathrm{ml}$., the erythrocyte count fell sharply, massive haemolysis occurred and death occurred within a few hours. An amount of antiserum that killed 15 per cent of the mice gave the maximum depression of haematocrit (to 10 per cent of its normal value) $30 \mathrm{~h}$ after injection. The hacmatocrit returned to 50 per cent of its original value after 6 days, and to 90 per cent on the tenth day. Mice that survived 4 days after a single injection, or after a series of injections, rarely died later.

Table 1. In vivo TESTS OF $\gamma$-GLOBULIN FROM A RABBIT ANTISERUM PREPARED AGAINST GARDNER LEUKAEMIA CELLS

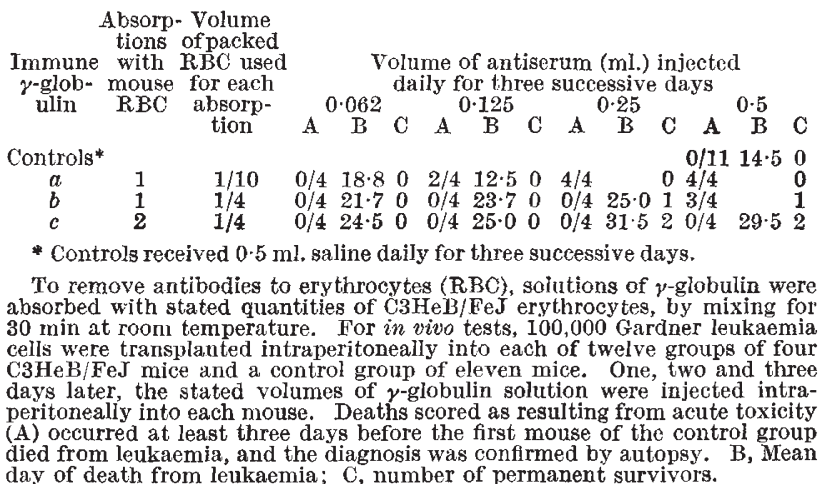

The acute toxicity of potent antileukaemia sera was progressively removed by absorptions with mouse erythrocytes (Table 1). These absorptions greatly decreased antibody activity against erythrocytes. For the three immune $\gamma$-globulin preparations $a, b$ and $c$ (Table 1), there were sharp reductions in haemagglutination potency ${ }^{19}$ (from 760 , to 190 and to 24), in haemolytic potency ${ }^{19}$ (from 3,200 , to 2,080 and to 560 ), and in potency of complement $C^{\prime}$ fixation $^{12}$ by mouse erythrocytes (from 1,280 , to 304 and to 0 ), respectively. In contrast, antibody activity against leukaemia cells was only slightly decreased. For the same series of absorptions (Table 1), this decrease was less than 25 per cent, as determined both by immune cytolysis ${ }^{16,17}$ and by $C^{\prime}$ fixation ${ }^{12}$ against Gardner leukaemia cells.

The results indicate that antibodies to mouse erythrocytes are responsible for the acute toxicity of potent hyperimmune antileukaemia sera ${ }^{20,21}$. The effects of such antisera are adequately predicted by the number of units of haemagglutination potency administered (Fig. 1). Below a certain threshold, such sera are not acutely toxic. Therapy experiments indicate that prolongation in the lifespan of mice increases in direct proportion to the total units of cytolytic potency injected on successive days (Fig. 2). With Gardner leukaemia, the threshold for therapeutic effect occurred at relatively few units of cytolytic potency; when many units were administered, permanent survivors were obtained in some experiments (Fig. 2). In contrast, tho threshold was much higher for leukaemia L1210; the number of cytolytic potency units could not be sufficiently increased to achieve long term survival of a single DBA/2J mouse inoculated with 